\title{
Prevalence and Predictors of Depression, Anxiety, and Stress among Youth at the Time of COVID-19: An Online Cross-Sectional Multicountry Study
}

\author{
Omar Al Omari (D, ${ }^{1,2}$ Sulaiman Al Sabei, ${ }^{1}$ Omar Al Rawajfah, ${ }^{1,3}$ Loai Abu Sharour, \\ Khalid Aljohani, ${ }^{5}$ Khaled Alomari ${ }^{D},{ }^{1}$ Lina Shkman, ${ }^{1}$ Khloud Al Dameery, ${ }^{1}$ Ahmed Saifan, ${ }^{6}$ \\ Bushara Al Zubidi $\mathbb{D}^{7}{ }^{7}$ Samh Anwar $\mathbb{D}^{8},{ }^{8}$ and Fadwa Alhalaiqa9 \\ ${ }^{1}$ Sultan Qaboos University, College of Nursing, Muscat, Oman \\ ${ }^{2}$ Curtin University, School of Nursing, Midwifery and Paramedicine, Perth, Western Australia, Australia \\ ${ }^{3}$ College of Nursing, Al al-Bayt University, Jordan \\ ${ }^{4}$ ALZaytoonah University of Jordan, College of Nursing, Amman, Jordan \\ ${ }^{5}$ Taibah University, College of Nursing, Saudi Arabia \\ ${ }^{6}$ Applied Science Private University, Amman, Jordan \\ ${ }^{7}$ Baghdad University, College of Nursing, Baghdad, Iraq \\ ${ }^{8}$ Alexandria University, College of Nursing, Alexandria, Egypt \\ ${ }^{9}$ Philadelphia University, College of Nursing, Amman, Jordan
}

Correspondence should be addressed to Omar Al Omari; o.alomari@squ.edu.om

Received 17 July 2020; Revised 15 September 2020; Accepted 25 September 2020; Published 6 October 2020

Academic Editor: Giovanni Galeoto

Copyright ( 2020 Omar Al Omari et al. This is an open access article distributed under the Creative Commons Attribution License, which permits unrestricted use, distribution, and reproduction in any medium, provided the original work is properly cited.

\begin{abstract}
Depression and anxiety are prevalent mental illnesses among young people. Crisis like the Coronavirus Disease 2019 (COVID-19) pandemic may increase the current prevalence of these illnesses. A cross-sectional, descriptive design was used to (1) explore the prevalence of depression, anxiety, and stress among youth and (2) identify to what extent certain variables related to COVID-19 could predict depression, anxiety, and stress (DAS) among young people in six different countries. Participants were requested to complete an online survey including demographics and the DAS scale. A total of 1,057 participants from Oman ( $n=155)$, Saudi Arabia $(n=121)$, Jordan $(n=332)$, Iraq $(n=117)$, United Arab Emirates $(n=147)$, and Egypt $(n=182)$ completed the study. The total prevalence of depression, anxiety, and stress was $57 \%, 40.5 \%$, and $38.1 \%$, respectively, with no significant differences between countries. Significant predictors of stress, anxiety, and depression were being female, being in contact with a friend and/or a family member with mental illness, being quarantined for 14 days, and using the internet. In conclusion, COVID-19 is an epidemiological crisis that is casting a shadow on youths' DAS. The restrictions and prolonged lockdowns imposed by COVID-19 are negatively impacting their level of DAS. Healthcare organisations, in collaboration with various sectors, are recommended to apply psychological first aid and design appropriate educational programmes to improve the mental health of youth.
\end{abstract}

\section{Introduction}

Since the beginning of 2020, Coronavirus Disease 2019 (COVID-19) has headed global news. The story started back in December 2019 in Wuhan, China, when an outbreak of cases infected with a novel, deadly virus was reported. Later, the causing microorganism was found to be a new type of coronavirus, and the disease was labelled COVID-19 [1]. Between January and March 2020, the disease spread to more than 110 countries and the number of cases outside China increased 13-fold [2]. As a result, the World Health Organisation (WHO) declared COVID-19 a pandemic on 11 March 2020 [3]. As of 5 May, there were over 3.6 million confirmed cases and over 251,898 deaths worldwide, according to the 
Johns Hopkins Coronavirus Resource Center [4]. Countries initiated a series of measures to break the chain of infection and control the pandemic, including local and international travel bans, bans on large gatherings, suspension of public transport, closure of schools and universities and of business, social distancing, stay-at-home orders, and curfews [5]. These restrictions and the uncertain trend of the disease can significantly affect mental wellbeing. The educational [6] and economic [7] sectors were almost paralysed, and healthcare systems were overwhelmed by the flood of new cases. The pandemic has become the central concern of people around the world, and they spend most of their time watching and reading the news around it. In general, people are afraid, angry, anxious, and stressed [8].

Youth is defined as age 15 to 24 years, and it includes middle and late adolescence [9]. It is characterised by ongoing changes in physical, psychological, and social dimensions [10]. For healthy growth and development, youth needs to have a sense of belonging, love, achievement, and independence and to have a purpose in life [10]. During this developmental stage, many types of behaviour are developed which can lead to either normalcy or mental health illness [11, 12]. Depression, anxiety, and stress (DAS) are the most common mental illnesses among youth [13]. There are shared symptoms between anxiety and depression. However, psychologists can differentiate DAS diagnoses using a tripartite model [14]. This model postulates that anxiety and depression share common characteristics of negative effect but can be distinguished by low positive effect associated with depression and high physiological hyperarousal associated with anxiety [14]. In previous studies, the prevalence of stress among Iraqi youths was found to be $51.1 \%$ [15]; the prevalence of anxiety among youths in Oman, Jordan, Egypt, Iraq, and Saudi Arabia was 17\% [16], 42.1\% [17], 41.2\% [15], and $63.5 \%$ [18], respectively; and the prevalence of youth depression was $73.8 \%$ in Jordan [17], 28.6\% in Egypt [19], 17\% in Oman [16], 29.4\% in Iraq [15], and 71\% in Saudi Arabia [18]. Given such alarming statistics, the American Academy of Child and Adolescent Psychiatry (AACAP) recommends regular screening of young people for mental illness [20].

Youth in the Middle East have common backgrounds as the majority speak Arabic and are Muslims. Moreover, COVID-19 has impacted all Middle Eastern countries, which have taken similar measures to restrain the pandemic including suspension of schools and universities and stay-at-home orders. Giving mental illness special attention at this time is crucial. Several studies have linked crises to developing mental illnesses such as DAS [21, 22]. If left undiagnosed and untreated, mental illness can negatively impact the development, social life, and even future careers of young people [23]. Positive relationships have been found between DAS and poor academic achievement [24], poor peer friendship [25], substance misuse [26, 27], and suicide attempts [28]. The impact of COVID-19 may play a significant role in triggering or worsening signs, symptoms, and eventual development of mental illness. With limited knowledge about COVID-19, the uncertainty of its trends, the worry over getting the disease itself, and drastic changes in lifestyles and livelihoods, the mental health of youth has become a serious concern [29]. The purpose of this study was to explore the prevalence of DAS among youth from six Middle Eastern countries and to identify the extent to which some COVID19-related variables could predict DAS among them.

\section{Materials and Methods}

A cross-sectional descriptive design was used to assess the relationship between DAS during the COVID-19 pandemic. The target population was young people aged 15 to 24 , as defined by the United Nations [9]. Between 1 and 15 April 2020, an online survey was distributed using social media platforms to recruit participants in 11 countries: Oman, Kuwait, Saudi Arabia, UAE, Qatar, Bahrain, Iraq, Jordan, Lebanon, Palestine, and Egypt. However, respondents from only six countries completed the survey. WhatsApp and Facebook were the main social media platforms used in the study settings. The inclusion criteria were (1) willingness to participate, (2) being 15 to 24 years old at the time of the study, (3) ability to read and type in Arabic, and (4) residence in one of the countries included in the study at the time of the survey.

2.1. Sample Size. To have a medium effect size (Cohen's f2 $=0.15)$, statistical power is $80 \%$, probability level is 0.05 , and the estimated sample size from each country is 113 study participants [30]. 113 participants from each country were required to take part in the study.

2.2. Ethical Approval. Ethical approval was obtained from the study sites prior to data collection, and consent was assumed as completing the survey questions. Participants were informed that their participation was voluntary and that they could withdraw from the study at any point or choose not to answer any question. Participants' confidentiality was maintained as no identifying information was collected and findings will be disseminated only in aggregate.

2.3. Study Variables and Measurements. A structured questionnaire was used to collect information about (1) participants' sociodemographics including age; gender; educational level and type; presence of family members, friends, or colleagues with COVID-19; previous history of depression or anxiety; history of medication for depressive syndrome; frequency of watching news about COVID-19; and internet use; (2) depression; (3) anxiety; and (4) stress.

Several scales are available to measure depression symptoms, including the depression scale [31, 32] and Beck depression inventory-II [33]; however, the researchers made a deliberate decision to use the Depression, Anxiety, and Stress Scale (DASS) because it is available in the public domain, the Arabic version has been validated, it is sensitive to youth, and it measures depression, anxiety, and stress in the same survey. The short form of DASS is a 21 -item, 4point Likert scale where $0=$ does not apply to me at all; $1=$ applies to me to some degree, or some of the time; 2 =applies to me to a considerable degree, or a good part of my life; and 3 = applies to me very much, or most of the time.

The depression scale assesses a range of depressive syndromes including dysphoria, hopelessness, and lack of 
interest/involvement. The higher score indicates a higher level of depression, categorised by scores as normal (0-9 points), mild [10-13], moderate [14-20], and severe [2127]; scores of 28 and above indicate extremely severe depression [34].

The anxiety scale assesses the subjective experience of the anxiety effect, autonomic arousal, skeletal muscle effects, and situational anxiety. Scores are classified as normal ( $0-7$ points), mild $[8,9]$, moderate $[10-14]$, and severe [15-19], with scores of 20 or more indicating extremely severe anxiety [34].

The stress scale assesses difficulty relaxing, being irritable/overreactive and impatient, and being easily upset/agitated: normal (0-14), mild [15-18], moderate [19-25], and severe [26-33], with scores of 34 or more indicating extremely severe stress [34].

The Arabic version of DASS is available in the public domain [34]. The reliability (Cronbach's alpha $=0.88$ ) and construct validity of the Arabic version are well established [35].

2.4. Statistical Analysis Plan. Data were transferred from Google Forms to an Excel sheet and exported to SPSS version 23 for the analysis. Descriptive statistics were used to determine the frequencies, mean, and standard deviation and to describe sample demographics. Multivariate linear regression was conducted to identify the extent to which certain variables related to COVID-19 predict DAS among the participants. Statistical significance was set a priori at $p<0.05$.

\section{Results}

Over two weeks of data collection, 1,057 participants from six countries completed the survey. The majority of participants were female $756(71.5 \%)$, and the mean age was 21.01 $(\mathrm{SD}=1.69)$. Most $(1,048,99.1 \%)$ had never been diagnosed with mental illness and 91 (8.6\%) with chronic illnesses. The majority of participants were university students (762, $72.1 \%)$, with only $29(2.7 \%)$ in 9th grade. On average, participants had spent 9.74 hours $(S D=4.99)$ daily surfing the internet since COVID-19 was declared as a pandemic, compared with only 5.64 hours $(\mathrm{SD}=3.83$ ) daily before the outbreak. Almost two-thirds of the participants were following COVID-19 news by surfing the internet $(685,64.8 \%$ ) (see Table 1).

One-way ANOVA revealed that depression, anxiety, and stress were not statistically different between the six countries $(F=0.996, p=0.419 ; F=1.979, p=0.079$; and $F=1.841$, $p=0.102$, respectively). The prevalence of depression, anxiety, and stress was $57 \%, 40.5 \%$, and $38.1 \%$ among all participants. Participants from Saudi Arabia had the lowest rates, and Egyptian participants the highest prevalence (Table 2).

3.1. Multivariable Analysis. Three models were built to identify the predictors of depression, anxiety, and stress. The normality, linearity, heteroscedasticity, and independence of residuals were assessed. Bivariate analysis using an independent $t$-test was performed to assess whether there was a significant difference in the means between the independent variables and the three dependent variables depression, anx- iety, and stress, with other explanatory factors (Table 3). The Spearman correlation coefficient was used to test for bivariate correlation between the number of hours spent on the internet and the three dependent variables. The results revealed that depression, anxiety, and stress were positively associated with the number of hours spent on the internet after COVID19 with $r$ coefficient of $0.15,0.13$, and 0.17 ( $p>0.01$ ), respectively. Only variables with statistically significant associations with the dependent variables were entered into the preliminary regression model (For more detail, see Table 3 ). The backward approach was employed, and explanatory variables which were not significant were excluded to build the final linear regression model.

3.1.1. Depression. The final model was statistically significant compared to the constant $(F=18.199, p<0.001)$ with final variables of female gender, having a family member with mental illness, having a friend with mental illness, exposed to an infected person with COVID-19, being quarantined for 14 days, using the internet after COVID-19, and being at risk of infection as significant predictors of depression. $R^{2}$ and adjusted $R^{2}$ of the final model were 0.108 and $=0.102$, respectively (Table 4 , model 1 ).

3.1.2. Anxiety. The final model was statistically significant compared to the constant $(F=23.4, p<0.001)$. Significant predictors of anxiety included female gender, having a friend with mental illness, exposed to a person with COVID-19, using the internet after COVID-19, and being at risk of infection. $R^{2}$ and adjusted $R^{2}$ of the final model were 0.100 and $=0.096$, respectively (Table 4 , model 2 ).

3.1.3. Stress. The final model was statistically significant compared to the constant $(F=23.4, p<0.001)$. Significant predictors of anxiety included female gender, having a family member with mental illness, having a friend with mental illness, having a relative diagnosed with COVID-19, using the internet after COVID-19, and being at risk of infection with COVID-19. $R^{2}$ and adjusted $R^{2}$ of the final model were 0.122 and 0.117 , respectively (Table 4 , model 3 ).

\section{Discussion}

The aim of the current study was to explore the prevalence of DAS among youth in six Middle Eastern countries and to identify the associated predictors. The prevalence of anxiety was found to range from $33.1 \%$ in Saudi Arabia to $51.6 \%$ in Egypt, with a total prevalence of $40.5 \%$ in the six countries. These results are consistent with previously reported prevalence rates $[16,17,19]$. The prevalence of depression in the current study ranged from $47.9 \%$ in Saudi Arabia to $64.8 \%$ in Egypt with a total prevalence of 57\%. In previous studies, the reported rates of depression in Egypt [19], Oman [16], and Iraq [15] were lower than those identified in this study. However, the depression rates in Jordan [17] and Saudi Arabia [18] were higher than the identified rates in this study. The inconsistency of some prevalence rates of DAS with previous literature may be related to different survey methods, recruitment of young people with different age groups, and 
TABLE 1: Sample characteristics $(N=1,057)$.

\begin{tabular}{|c|c|c|c|}
\hline Variable & $n(\%)$ & Variable & $n(\%)$ \\
\hline Gender & & \multicolumn{2}{|c|}{ Exposed to person with COVID-19 } \\
\hline Male & $301(28.5)$ & Yes & $14(1.3)$ \\
\hline Female & $756(71.5)$ & No & $1,043(98.7)$ \\
\hline Country & & \multicolumn{2}{|c|}{$\begin{array}{l}\text { Am I at risk of being infected with } \\
\text { COVID-19? }\end{array}$} \\
\hline Oman & $155(14.7)$ & Yes & $437(41.3)$ \\
\hline Jordan & $335(31.7)$ & No & $620(58.7)$ \\
\hline Saudi Arabia & $121(11.4)$ & & \\
\hline Iraq & $117(11.1)$ & \multicolumn{2}{|c|}{ I have been quarantined for 14 days } \\
\hline UAE & $147(13.9)$ & Yes & $288(27.2)$ \\
\hline Egypt & $182(17.2)$ & No & $769(72.8)$ \\
\hline Level of education & & \multicolumn{2}{|c|}{ Do you follow the COVID news? } \\
\hline 9th & $29(2.7)$ & Yes & $980(92.7)$ \\
\hline 10th & $81(7.7)$ & No & $77(7.3)$ \\
\hline 11th & $22(2.1)$ & \multicolumn{2}{|c|}{$\begin{array}{l}\text { I know someone diagnosed with } \\
\text { COVID-19 }\end{array}$} \\
\hline 12 th & $163(15.4)$ & No & $982(92.9)$ \\
\hline \multirow[t]{2}{*}{ University } & $762(72.0)$ & My friend & $46(4.4)$ \\
\hline & & Family member & $29(3.0)$ \\
\hline Do you have a mental illness? & & \multicolumn{2}{|c|}{$\begin{array}{l}\text { My main source of information about } \\
\text { COVID-19 is }\end{array}$} \\
\hline Yes & $8(0.9)$ & The internet & $685(64.8)$ \\
\hline No & $1,048(99.1)$ & TV & $353(33.4)$ \\
\hline Friend diagnosed with mental illness & & Friends & $19(1.8)$ \\
\hline Yes & $54(5.1)$ & & \\
\hline No & $1,003(94.9)$ & & \\
\hline \multicolumn{4}{|l|}{ Family member diagnosed with mental illness } \\
\hline Yes & $45(4.3)$ & & \\
\hline No & $1,011(95.7)$ & & \\
\hline \multicolumn{4}{|l|}{ Do you have chronic illness } \\
\hline Yes & $91(8.6)$ & & \\
\hline No & $966(91.4)$ & & \\
\hline Variable & $M(\mathrm{SD})$ & & \\
\hline Age & $21.0(1.7)$ & & \\
\hline Depression score & $13.2(10.4)$ & & \\
\hline Anxiety score & $7.6(7.9)$ & & \\
\hline Stress score & $13.4(10.4)$ & & \\
\hline Use of internet before COVID-19 (hours per day) & $5.6(3.8)$ & & \\
\hline Use of internet after COVID-19 (hours per day) & $9.7(5.0)$ & & \\
\hline
\end{tabular}

use of different tools. The findings of the current study were similar to those of previous studies, which suggests that the COVID-19 pandemic has no significant impact on the selected DAS variables.

One possible explanation is that at the time of this study, the epidemic had not peaked, and the number of reported cases was relatively insignificant in the study settings. In order for people to be psychologically affected, two of the following four conditions should be met: (1) a large number of injuries and casualties should be reported, (2) mass damage to property, (3) disruption of social support, and [4] ongoing economic problems [36]. At the time of the data collection, most of these conditions were not present, which may explain the relatively similar prevalence rates of DAS among youth before and after COVID-19.

In the current study, several factors were associated with DAS prevalence rates. Some of these variables were also reported in previous literature, including female gender, having a friend and/or family member diagnosed with mental illness, and using the internet. Young females have higher levels of DAS [37, 38]. Mental illnesses affect not only the diagnosed person but also the surrounding people, such as 
TABle 2: Prevalence of depression, anxiety, and stress $(N=1,057)$.

\begin{tabular}{|c|c|c|c|c|}
\hline Countries & Level & $\begin{array}{c}\text { Depression } \\
n(\%)\end{array}$ & $\begin{array}{c}\text { Anxiety } \\
n(\%)\end{array}$ & $\begin{array}{l}\text { Stress } \\
n(\%)\end{array}$ \\
\hline \multirow{5}{*}{ Jordan } & Normal & $147(44)$ & $204(60.9)$ & $214(64)$ \\
\hline & Mild & $53(16)$ & $30(9.0)$ & $31(9.3)$ \\
\hline & Moderate & $65(19.4)$ & $55(16.6)$ & $36(10.7)$ \\
\hline & Severe & $24(7.3)$ & $11(3.3)$ & $31(9.3)$ \\
\hline & Extremely severe & $46(13.7)$ & $35(10.4)$ & $23(6.9)$ \\
\hline \multirow{5}{*}{ Saudi Arabia } & Normal & $63(52.1)$ & $81(66.9)$ & $84(69.4)$ \\
\hline & Mild & $14(11.6)$ & $3(2.5)$ & $10(8.3)$ \\
\hline & Moderate & $16(13.2)$ & $20(16.5)$ & $9(7.4)$ \\
\hline & Severe & $10(8.3)$ & $5(4.1)$ & $10(8.3)$ \\
\hline & Extremely severe & $18(14.9)$ & $12(9.9)$ & $8(6.6)$ \\
\hline \multirow{5}{*}{ Oman } & Normal & $68(43.9)$ & $94(60.6)$ & $107(69)$ \\
\hline & Mild & $26(16.8)$ & $11(7.1)$ & $10(6.5)$ \\
\hline & Moderate & $28(18.1)$ & $22(14.2)$ & $18(11.6)$ \\
\hline & Severe & $17(11)$ & $11(7.1)$ & $16(10.3)$ \\
\hline & Extremely severe & $16(10.3)$ & $17(11)$ & $4(2.6)$ \\
\hline \multirow{5}{*}{ Iraq } & Normal & 49 (41.9) & $71(60.7)$ & $60(51.3)$ \\
\hline & Mild & $18(15.4)$ & $7(6)$ & $21(17.9)$ \\
\hline & Moderate & $24(20.5)$ & $16(13.7)$ & $16(13.7)$ \\
\hline & Severe & $14(12)$ & $9(7.7)$ & $16(13.7)$ \\
\hline & Extremely severe & $12(10.3)$ & $14(12)$ & $4(3.4)$ \\
\hline \multirow{5}{*}{ UAE } & Normal & $62(42.2)$ & $91(61.9)$ & $85(57.8)$ \\
\hline & Mild & $21(14.3)$ & $10(6.8)$ & $19(12.9)$ \\
\hline & Moderate & $28(19.0)$ & $19(12.9)$ & $21(14.3)$ \\
\hline & Severe & $19(12.9)$ & $11(7.5)$ & $16(10.9)$ \\
\hline & Extremely severe & $17(11.6)$ & $16(10.9)$ & $6(4.1)$ \\
\hline \multirow{5}{*}{ Egypt } & Normal & $64(35.2)$ & $88(48.4)$ & $104(57.1)$ \\
\hline & Mild & $28(15.4)$ & $13(7.1)$ & $26(14.3)$ \\
\hline & Moderate & $42(23.1)$ & $40(22)$ & $22(12.1)$ \\
\hline & Severe & $24(13.2)$ & $16(8.8)$ & $15(8.2)$ \\
\hline & Extremely severe & $24(13.2)$ & $25(13.7)$ & $15(8.2)$ \\
\hline \multirow{5}{*}{ Total } & Normal & $453(43.0)$ & $629(59.6)$ & $654(61.9)$ \\
\hline & Mild & $160(15.1)$ & $74(7)$ & $117(11.1)$ \\
\hline & Moderate & $203(19.2)$ & $172(16.2)$ & $122(11.5)$ \\
\hline & Severe & $108(10.2)$ & $63(6.0)$ & $104(9.8)$ \\
\hline & Extremely severe & $133(12.5)$ & $119(11.2)$ & $133(12.5)$ \\
\hline
\end{tabular}

family members and friends. Research studies have found that children who are in close contact with mentally ill people are at a greater risk of developing mental illness themselves $[39,40]$. There is a need to establish a support system for young people living in families with mentally ill members. The use of the internet was found to be a predictor of DAS in this study. The lockdown, suspension of studies, and moving to online learning have significantly increased the use of the internet among youth from an average of 5.46 hours a day before COVID-19 to 9.74 hours a day. The current finding is well reported in the literature [41]. Therefore, healthcare organisations in collaboration with ministries of telecommunications are strongly encouraged to design and provide specific psychological promotion programmes for youth during this pandemic with the aim of promoting their mental health.

Income, age, academic status, study in a capital city, and health-related condition were other predictors identified in previous literature [42-44] but not measured in the current study. Older students are at greater risk of DAS [43]. Youth with health and academic problems were found to have greater stress [42]. Those living in low- and middle-income families have higher rates of DAS than those in highincome families [43]. In the current study, the majority of participants declined to answer the income question, and therefore, it was not included in the analysis. However, it was interesting to observe that the rate for DAS among youth from high-income countries such as Oman, Saudi Arabia, 
TABLE 3: Bivariate analysis of depression, anxiety, and stress.

\begin{tabular}{|c|c|c|c|c|c|c|c|}
\hline Variable & Category & $\begin{array}{c}\text { Depression } \\
M(\mathrm{SD})\end{array}$ & $p$ & $\begin{array}{l}\text { Anxiety } \\
M(\mathrm{SD})\end{array}$ & $p$ & $\begin{array}{c}\text { Stress } \\
M(\mathrm{SD})\end{array}$ & $p$ \\
\hline \multirow{2}{*}{ Gender } & Male & $10.9(10.0)$ & \multirow{2}{*}{$<0.001$} & $5.9(7.2)$ & \multirow{2}{*}{$<0.001$} & $10.7(9.7)$ & \multirow{2}{*}{$<0.001$} \\
\hline & Female & $14.1(10.4)$ & & $8.3(8.1)$ & & $14.5(10.4)$ & \\
\hline \multirow{2}{*}{ Do you have a family member diagnosed with mental illness } & No & $12.9(10.2)$ & \multirow{2}{*}{$<0.001$} & $7.5(7.8)$ & \multirow{2}{*}{0.056} & $13.1(10.1)$ & \multirow{2}{*}{$<0.001$} \\
\hline & Yes & $20.1(12.1)$ & & $9.8(9.6)$ & & $19.8(12.8)$ & \\
\hline \multirow{2}{*}{ One friend diagnosed with mental illness } & No & $12.9(10.2)$ & \multirow{2}{*}{$<0.001$} & $7.4(7.7)$ & \multirow{2}{*}{$<0.001$} & $13.1(10.1)$ & \multirow{2}{*}{$<0.001$} \\
\hline & Yes & $19.0(12.3)$ & & $11.8(10.5)$ & & $19.3(12)$ & \\
\hline \multirow{2}{*}{ Exposed to person with COVID-19 } & No & $13.1(10.3)$ & \multirow{2}{*}{0.005} & $7.5(7.8)$ & \multirow{2}{*}{$<0.001$} & $13.3(10.2)$ & \multirow{2}{*}{0.002} \\
\hline & Yes & $21.0(13.6)$ & & $15(10.0)$ & & $21.9(10.8)$ & \\
\hline \multirow{2}{*}{ I have a relative diagnosed with COVID-19 } & No & $12.9(10.3)$ & \multirow{2}{*}{0.002} & $7.4(7.8)$ & \multirow{2}{*}{$<0.001$} & $13.1(10.3)$ & \multirow{2}{*}{$<0.001$} \\
\hline & Yes & $17.7(10.5)$ & & $12.4(7.8)$ & & $19.1(9.1)$ & \\
\hline \multirow{2}{*}{ I am at risk of being infected with COVID-19 } & No & $11.3(9.8)$ & \multirow{2}{*}{$<0.001$} & $6.0(6.9)$ & \multirow{2}{*}{$<0.001$} & $11.4(9.7)$ & \multirow{2}{*}{$<0.001$} \\
\hline & Yes & $15.8(10.5)$ & & $9.9(8.6)$ & & $16.2(10.5)$ & \\
\hline \multirow{2}{*}{ I have been quarantined for 14 days } & No & $12.6(10.3)$ & \multirow{2}{*}{0.002} & $7.3(8)$ & \multirow{2}{*}{0.027} & $12.8(10.3)$ & \multirow{2}{*}{0.002} \\
\hline & Yes & $14.8(10.4)$ & & $8.5(7.6)$ & & $15.0(10.2)$ & \\
\hline
\end{tabular}

TABLE 4: Linear regression model of independent variables that predict depression, anxiety, and stress.

\begin{tabular}{|c|c|c|c|c|c|c|c|}
\hline & \multirow{2}{*}{$\begin{array}{c}\text { Unstandardised coefficient } \\
\qquad B\end{array}$} & \multicolumn{4}{|c|}{ Standardised coefficient } & \multicolumn{2}{|c|}{$95 \% \mathrm{CI}$ for $\beta$} \\
\hline & & SE & $\beta$ & $t$ & $p$ & Lower bound & Upper bound \\
\hline \multicolumn{8}{|l|}{ Model one: predictors of depression } \\
\hline Constant & -16.160 & 3.579 & & -4.515 & $<0.001$ & -16.160 & 3.579 \\
\hline Gender & 2.451 & 0.678 & 0.106 & 3.613 & $<0.001$ & 0.678 & 2.451 \\
\hline Family member with mental illness & 5.357 & 1.563 & 0.104 & 3.427 & 0.001 & 5.357 & 1.563 \\
\hline Friend with mental illness & 3.718 & 1.437 & 0.079 & 2.588 & 0.010 & 3.718 & 1.437 \\
\hline Exposed to person with COVID-19 & 5.883 & 2.674 & 0.065 & 2.200 & 0.028 & 5.883 & 2.674 \\
\hline Risk of having COVID-19 & 3.786 & 0.626 & 0.179 & 6.049 & $<0.001$ & 3.786 & 0.626 \\
\hline Quarantined 14 days & 1.456 & 0.686 & 0.062 & 2.122 & 0.034 & 1.456 & 0.686 \\
\hline Using the internet & 0.254 & 0.061 & 0.122 & 4.149 & $<0.001$ & 0.254 & 0.061 \\
\hline \multicolumn{8}{|l|}{ Model two: predictors of anxiety } \\
\hline Constant & -11.875 & 2.547 & & -4.663 & $<0.001$ & -16.873 & -6.878 \\
\hline Gender & 2.002 & 0.518 & 0.114 & 3.868 & $<0.001$ & 0.987 & 3.018 \\
\hline Friend with mental illness & 3.579 & 1.060 & 0.099 & 3.376 & 0.001 & 1.499 & 5.659 \\
\hline Exposed to person with COVID-19 & 5.870 & 2.047 & 0.085 & 2.868 & 0.004 & 1.853 & 9.886 \\
\hline Risk of having COVID-19 & 3.366 & 0.478 & 0.209 & 7.047 & $<0.001$ & 2.429 & 4.303 \\
\hline Using the internet & 0.162 & 0.047 & 0.102 & 3.466 & 0.001 & 0.070 & 0.254 \\
\hline \multicolumn{8}{|l|}{ Model three: predictors of stress } \\
\hline Constant & -12.188 & 2.471 & & -4.933 & $<0.001$ & -17.036 & -7.339 \\
\hline Gender & 3.077 & 0.668 & 0.134 & 4.605 & $<0.001$ & 1.766 & 4.389 \\
\hline Family with mental illness & 4.849 & 1.541 & 0.095 & 3.147 & 0.002 & 1.825 & 7.872 \\
\hline Friend with mental illness & 3.887 & 1.419 & 0.083 & 2.740 & 0.006 & 1.103 & 6.670 \\
\hline Relative with COVID-19 & 2.154 & 0.801 & 0.078 & 2.688 & 0.007 & 0.582 & 3.727 \\
\hline Risk of having COVID-19 & 4.327 & 0.611 & 0.206 & 7.077 & $<0.001$ & 3.128 & 5.527 \\
\hline Using the internet & 0.275 & 0.061 & 0.133 & 4.540 & $<0.001$ & 0.156 & 0.394 \\
\hline
\end{tabular}

and UAE was comparable to that from lower-income countries such as Jordan, Egypt, and Iraq. It is clear that DAS is a mixture of biological, personal, spiritual, emotional, and social factors and that income is only one factor. There is a need to regularly screen youth and identify the newly evolved variables associated with DAS [20].

New variables identified in the current study that are directly related to the current epidemiological crisis have not 
been reported previously. These include contacting a person with COVID-19, being quarantined for 14 days, being at risk of infection from COVID-19, and the increased use of the internet after COVID-19's appearance. The ambiguity of COVID-19, being labelled as a deadly disease, the disruption to daily activity, and believing being at risk from COVID-19 were identified as factors that increase the level of fear and DAS among youth. This finding is supported by previous research studies $[45,46]$. Another study found that the stress level of young people who had been quarantined was four times higher than that of their counterparts who had not been [47]. Families can play a significant role in minimising the effect of staying at home. Parents need to let young people express their feelings and fears about the current situation. They also need to make an effort to increase family time to provide youths with a sense of security.

With stay-at-home orders and restrictions, governments should also consider finding new technological methods to prevent, screen, and manage potential mental illness. Online mental health services should be activated, as has been done in some countries [48]. Governments should adopt the same approach and establish online mental health clinics where people can be virtually screened and consulted. These clinics can help individuals to stay anonymous and encourage them to convey their feelings in a free environment. Another role for these clinics is to develop psychological programmes and educate young people about mental illnesses and how to learn about and counter them [49] and about COVID19. Providing mental healthcare virtually can help in reducing the prevalence of DAS. Countries need to establish creative methods to shift the attention of youth. For example, the Jordanian government created an online competition for the general public in order to distract them, and the Omani government in collaboration with telecommunication companies made mobile phone calls available for free so people can socialise and support each other. These activities need to be encouraged and adopted by the rest of the countries.

There was an inherited limitation in this study that could not be avoided. The sample composition restricts the potential generalisability of the findings. The distribution of the questionnaires via social media platforms is open to selection bias in terms of recruiting those who are using these tools and are willing to respond to a survey. This limitation was imposed by the restrictions on people's movement and on using paper in the targeted countries. The researchers therefore made a deliberate decision to use the online survey. In the future and when restrictions are removed, it is recommended to replicate the study to include a larger sample and include youth who do not have access to the internet. DASS is not a diagnostic tool for DAS. There is a need for more robust methods to screen youth for mental illness, such as psychiatric interviewing. The cross-sectional design is limited in establishing causal relationship, so there is a need for longitudinal studies addressing these issues more appropriately.

\section{Conclusion}

The current study addressed the current gap in the literature regarding the effects of COVID-19 on the mental health of youth. This was the first study of its kind to collect data from six different countries using a standardised method and one of the few studies to investigate the prevalence of DAS during the COVID-19 pandemic. Healthcare providers, policymakers, and decision-makers should consider the findings and recommendations of this study to establish new emergency plans to address the psychological needs of youths and to prevent and manage emerging mental illness in the future. The three models in the current study predict only $10-11 \%$ of variance in DAS among young people. This was expected, considering the complexity of human behaviours and response to stress. There is a need to repeat the current study and include other variables to have a better understanding of depression, anxiety, and stress among youth.

\section{Data Availability}

The SPSS data used to support the findings of this study are restricted by the Research and Ethics Committee in the College of Nursing at Sultan Qaboos University in order to protect patient privacy. Data are available from Dr. Omar Al Omari, o.alomari@squ.edu.om, for researchers who meet the criteria for access to confidential data.

\section{Conflicts of Interest}

No authors of this paper have any conflicts of interest.

\section{Acknowledgments}

This work was supported by the Omani Research Council (TRC) (grant number: RC/COVID-CON/FACN/20/01), Muscat, Oman.

\section{References}

[1] C. Young, Covid-19: Novel Coronavirus Content Free to Access, John Wiley \& Sons, Hoboken, New Jersey, 2020, https://novelcoronavirus.onlinelibrary.wiley.com/.

[2] WHO, WHO Director-General's opening remarks at the media briefing on COVID-19 - 20 April 2020https://www.who.int/dg/ speeches/detail/who-director-general-s-opening-remarks-atthe-media-briefing-on-covid-19-20-april-2020.

[3] WHO, Coronavirus disease (COVID-2019) RßD 2020, 2020, https://www.who.int/blueprint/priority-diseases/key-action/ novel-coronavirus/en/.

[4] Johns Hopkins University, COVID-19 Dashboard by the Center for Systems Science and Engineering (CSSE) at Johns Hopkins, Johns Hopkins, USA, 2020, https://coronavirus.jhu.edu/ map.html.

[5] M. Khatatbeh, "Efficacy of nationwide curfew to encounter spread of COVID-19: a case from Jordan," Frontiers in Public Health, vol. 8, no. 394, 2020.

[6] R. Armitage and L. B. Nellums, "Considering inequalities in the school closure response to COVID-19," The Lancet Global Health, vol. 8, no. 5, p. e644, 2020.

[7] M. Gupta, A. Abdelmaksoud, M. Jafferany, T. Lotti, R. Sadoughifar, and M. Goldust, "COVID-19 and economy," Dermatologic Therapy, no. article e13329, 2020. 
[8] T. Lancet, "COVID-19: learning from experience," The Lancet, vol. 395, no. 10229, p. 1011, 2020.

[9] United Nations, Definition of youth, 2020, https://www.un .org/en/sections/issues-depth/youth-0/index.html.

[10] Oklahoma State University, Understanding boys and girls: five basic needs of youth - Oklahoma State 4-H 2020, 2020, http:// 4h.okstate.edu/literature-links/lit-online/others/volunteer/4H .VOL.102UnderstandingBoysGirls_08.pdf/.

[11] C. J. Murray, R. M. Barber, K. J. Foreman et al., "Global, regional, and national disability-adjusted life years (DALYs) for 306 diseases and injuries and healthy life expectancy (HALE) for 188 countries, 1990-2013: quantifying the epidemiological transition," The Lancet, vol. 386, no. 10009, pp. 2145-2191, 2015.

[12] J. K. Das, R. A. Salam, Z. S. Lassi et al., "Interventions for adolescent mental health: an overview of systematic reviews," Journal of Adolescent Health, vol. 59, no. 4, pp. S49-S60, 2016.

[13] T. Hicks and S. Heastie, High school to college transition: a profile of the stressors, physical and psychological health issues that affect the first-year on-campus college student, 2008.

[14] L. A. Clark and D. Watson, "Tripartite model of anxiety and depression: psychometric evidence and taxonomic implications," Journal of abnormal psychology, vol. 100, no. 3, pp. 316-336, 1991.

[15] S. Al-Abbudi, "Prevalence of symptoms of depression, anxiety and stress among secondary school students in Baghdad. Iraq," International Journal of Current Research, vol. 10, no. 3, pp. 66257-66261, 2019.

[16] M. Afifi, A. Al Riyami, M. Morsi, and K. H. Al, "Depressive symptoms among high school adolescents in Oman," EMHJEastern Mediterranean Health Journal, vol. 12, no. Supp 2, pp. S126-S137, 2006.

[17] M. Z. Malak and A. H. Khalifeh, "Anxiety and depression among school students in Jordan: prevalence, risk factors, and predictors," Perspectives in psychiatric care, vol. 54, no. 2, pp. 242-250, 2018.

[18] R. Alharbi, K. Alsuhaibani, A. Almarshad, and A. Alyahya, "Depression and anxiety among high school student at Qassim region," Journal of family medicine and primary care, vol. 8, no. 2, pp. 504-510, 2019.

[19] R. A. Al Bahnasy, G. M. Abdel-Rasoul, O. A. Mohamed, N. R. Mohamed, and R. A. Ibrahem, "Prevalence of depression, anxiety, and obsessive-compulsive disorders among secondary school students in Menoufia governorate Egypt," Menoufia Medical Journal, vol. 26, no. 1, p. 44, 2013.

[20] R. Martini, R. Hilt, L. Marx et al., Best Principles for Integration of Child Psychiatry into the Pediatric Health Home, American Academy of Child \& Adolescent Psychiatry, Washington, DC, 2012.

[21] J. LeMoult, K. L. Humphreys, A. Tracy, J.-A. Hoffmeister, E. Ip, and I. H. Gotlib, "Meta-analysis: exposure to early life stress and risk for depression in childhood and adolescence," Journal of the American Academy of Child \& Adolescent Psychiatry, vol. 59, 2020.

[22] E. A. Holmes, R. C. O'Connor, V. H. Perry et al., "Multidisciplinary research priorities for the COVID-19 pandemic: a call for action for mental health science," The Lancet, vol. 366, no. 20 , p. $30168,2020$.

[23] J. S. Brown, E. Blackshaw, D. Stahl et al., "School-based early intervention for anxiety and depression in older adolescents: a feasibility randomised controlled trial of a self-referral stress management workshop programme ("DISCOVER")," Journal of Adolescence, vol. 71, pp. 150-161, 2019.

[24] M. A. S. M. Yasin and M. A. Dzulkifli, Differences in depression, anxiety and stress between low-and high-achieving students, 2011.

[25] M. H. W. Van Zalk, M. Kerr, S. J. Branje, H. Stattin, and W. H. Meeus, "It takes three: selection, influence, and de-selection processes of depression in adolescent friendship networks," Developmental Psychology, vol. 46, no. 4, pp. 927-938, 2010.

[26] Y. Li and R. M. Lerner, "Trajectories of school engagement during adolescence: implications for grades, depression, delinquency, and substance use," Developmental Psychology, vol. 47, no. 1, pp. 233-247, 2011.

[27] J. D. Buckner, R. G. Heimberg, A. H. Ecker, and C. Vinci, "A biopsychosocial model of social anxiety and substance use," Depression and anxiety, vol. 30, no. 3, pp. 276-284, 2013.

[28] D. T. Nguyen, C. Dedding, T. T. Pham, P. Wright, and J. Bunders, "Depression, anxiety, and suicidal ideation among Vietnamese secondary school students and proposed solutions: a cross-sectional study," BMC Public Health, vol. 13, no. 1, p. 1195, 2013.

[29] J. Zhang, W. Wu, X. Zhao, and W. Zhang, "Recommended psychological crisis intervention response to the 2019 novel coronavirus pneumonia outbreak in China: a model of West China Hospital," Precision Clinical Medicine, vol. 3, no. 1, pp. 3-8, 2020.

[30] S. P. Kellar and E. A. Kelvin, Munro's Statistical Methods for Health Care Research, Wolters Kluwer Health/Lippincott Williams \& Wilkins, New York, 2013.

[31] P. Massai, F. Colalelli, J. Sansoni et al., "Reliability and validity of the geriatric depression scale in Italian subjects with Parkinson's disease," Parkinson's Disease, vol. 2018, 6 pages, 2018.

[32] G. Galeoto, J. Sansoni, M. Scuccimarri et al., "A psychometric properties evaluation of the Italian version of the geriatric depression scale," Depression research and treatment, vol. 2018, 7 pages, 2018.

[33] A. T. Beck, R. A. Steer, and G. Brown, Beck depression inventory-II. Psychological Assessment, 1996.

[34] S. H. Lovibond and P. F. Lovibond, Manual for the Depression, Stress Scales Australia University of New South Wales, Anxiety, 1995.

[35] M. T. Moussa, P. Lovibond, R. Laube, and H. A. Megahead, "Psychometric properties of an arabic version of the depression anxiety stress scales (DASS)," Research on Social Work Practice, vol. 27, no. 3, pp. 375-386, 2015.

[36] F. H. Norris, M. J. Friedman, P. J. Watson, C. M. Byrne, E. Diaz, and K. Kaniasty, "60,000 disaster victims speak: part I. An empirical review of the empirical literature, 19812001," Psychiatry: Interpersonal and biological processes, vol. 65, no. 3, pp. 207-239, 2002.

[37] N. G. Khawaja, M. L. R. Santos, M. Habibi, and R. Smith, "University students' depression: a cross-cultural investigation," Higher Education Research \& Development, vol. 32, no. 3, pp. 392-406, 2013.

[38] M. Fawzy and S. A. Hamed, "Prevalence of psychological stress, depression and anxiety among medical students in Egypt," Psychiatry Research, vol. 255, pp. 186-194, 2017.

[39] L. M. A. Van Loon, M. O. M. Van de Ven, K. T. M. Van Doesum, C. L. M. Witteman, and C. M. H. Hosman, "The relation between parental mental illness and adolescent 
mental health: the role of family factors," Journal of Child and Family Studies, vol. 23, no. 7, pp. 1201-1214, 2014.

[40] W. Fekadu, A. Mihiretu, T. K. Craig, and A. Fekadu, "Multidimensional impact of severe mental illness on family members: systematic review,” BMJ open, vol. 9, no. 12, p. e032391, 2019.

[41] B. Keles, N. McCrae, and A. Grealish, "A systematic review: the influence of social media on depression, anxiety and psychological distress in adolescents," International Journal of Adolescence and Youth, vol. 25, no. 1, pp. 79-93, 2020.

[42] C. T. Sreeramareddy, P. R. Shankar, V. Binu, C. Mukhopadhyay, B. Ray, and R. G. Menezes, "Psychological morbidity, sources of stress and coping strategies among undergraduate medical students of Nepal," BMC Medical education, vol. 7, no. 1, p. 26, 2007.

[43] K. Shamsuddin, F. Fadzil, W. S. W. Ismail et al., "Correlates of depression, anxiety and stress among Malaysian university students," Asian journal of psychiatry, vol. 6, no. 4, pp. 318323, 2013.

[44] F. B. Mayer, I. S. Santos, P. S. Silveira et al., "Factors associated to depression and anxiety in medical students: a multicenter study," BMC medical education, vol. 16, no. 1, p. 282, 2016.

[45] American Psychological Association, Finding local mental health resources during the COVID-19 crisis, American Psychological Association, Washington, DC, 2020, https://www .apa.org/topics/covid-19/local-mental-health.

[46] A. Abramson, Coronavirus threat escalates fears - and bigotry, American Psychological Association, Washington, DC, 2020, https://www.apa.org/news/apa/2020/02/coronavirusthreat.

[47] G. Sprang and M. Silman, "Posttraumatic stress disorder in parents and youth after health-related disasters," Disaster medicine and public health preparedness, vol. 7, no. 1, pp. 105-110, 2013.

[48] L. Bufka, Speaking of Psychology: managing your mental health during COVID-19, American Psychological Association, Washington, DC, 2020, https://www.apa.org/research/action/ speaking-of-psychology/covid-19-mental-health.

[49] O. Al Omari, D. Wynaden, A. Alkhawaldeh et al., "Knowledge and attitudes of young people toward mental illness: a cross sectional study," in Comprehensive child and adolescent nursing, pp. 1-13, 2019. 